\title{
ANÁLISE FITOQUÍMICA DAS FOLHAS DE Punica granatum LINN (PUNICACEAE) POR CROMATOGRAFIA EM CAMADA DELGADA
}

\author{
A. S. de OLIVEIRA ${ }^{1}$, R. T. M. RAMOS ${ }^{1,2}$, M. R. A. FERREIRA ${ }^{1,2}$, L. A. L. SOARES ${ }^{1,2}$.
}

${ }^{1}$ Universidade Federal de Pernambuco, Laboratório de Farmacognosia, Departamento de Ciências Farmacêuticas

${ }^{2}$ Universidade Federal de Pernambuco, Centro de Biociências, Programa de Pósgraduação em Inovação Terapêutica

E-mail para contato: amandaa.samson@gmail.com

RESUMO - Punica granatum (Punicaceae), espécie popularmente conhecida como romanzeira ou romã, destaca-se na medicina tradicional por apresentar propriedades biológicas, tais como antifúngica, anti-inflamatória, antidiabética $e$ anticancerígena. Essas atividades se devem à presença de compostos do metabolismo secundário, logo a triagem fitoquímica é de fundamental importância para garantir a correta caracterização química da espécie. Assim, o objetivo do estudo foi realizar a triagem fitoquímica por cromatografia em camada delgada (CCD) das folhas de romã. As cromatoplacas foram obtidas utilizando a metodologia proposta por Wagner e Bladt (1996). Os resultados evidenciaram a presença de taninos condensados e hidrolisáveis, flavonoides, derivados cinâmicos, açucares redutores, saponinas, terpenos e esteroides.

Palavras-chave: Caracterização química; CCD; Romã.

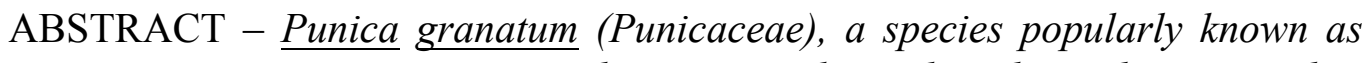
romanzeira or pomegranate, stands out in traditional medicine because it has biological properties such as antifungal, antiinflammatory, antidiabetic, and anticancer. These activities are due to the presence of compounds of the secondary metabolism, so the phytochemical screening is of fundamental importance to ensure the correct chemical characterization of the species. Thus, the objective of the study was to perform phytochemical screening by thin-layer chromatography (TLC) of pomegranate leaves. Chromateplates were obtained using the methodology proposed by Wagner and Bladt (1996). The results evidenced the presence of condensed e hydrolysable tannins, flavonoids, cinnamic derivatives, reducing sugars, saponins, terpenes and steroids.
\end{abstract}

Keywords: Chemical characterization; Pomegranate; TLC. 


\section{INTRODUÇÃO}

Punica granatum Linn (Punicaceae) popularmente conhecida como romanzeira ou romã, é uma espécie encontrada em regiões áridas do Sudeste Asiático, das Índia Oriental, da África tropical e da América (JURENKA, 2008). Esta espécie destaca-se na medicina tradicional por apresentar diversas propriedades biológicas, tais como antifúngica (FRIAS; KOZUSNY-ANDREANI, 2009), anti-inflamatória (FREITAS et al., 2015), antidiabética e anticancerígena (SARATALE et al., 2017). Para aprofundar o conhecimento farmacológico da espécie, a análise da sua composição química, com a finalidade de identificar grupos de metabólitos secundários, tem papel fundamental para esclarecer os responsáveis por desencadear as ações terapêuticas.

Entre as metodologias descritas na literatura que podem ser empregadas para caracterização fitoquímica, destaca-se a cromatografia em camada delgada (CCD). Trata-se de uma técnica qualitativa, bastante utilizada para identificação de constituintes químicos devido sua rapidez de execução, simplicidade e baixo custo (LINI et al., 2014), cujo parâmetro auxilia na investigação de compostos químicos. Diante do exposto, o objetivo desse trabalho foi realizar a análise fitoquímica do extrato metanólico das folhas de P. granatum por CCD para identificar metabólitos secundários, que poderá orientar estudos para novas abordagens biológicas.

\section{MATERIAIS E MÉTODOS}

As folhas de $P$. granatum foram coletadas em Recife-PE (91673). O material vegetal foi seco em estufa $\left(82 / 480\right.$, Lucadema $\left.{ }^{\circledR}\right)$ durante de 7 dias a $40{ }^{\circ} \mathrm{C}$ e posteriormente pulverizado em moinho de facas (Tipo Willye TE-680, Tecnal ${ }^{\circledR}$ ). Em seguida, $1 \mathrm{~g}$ da droga vegetal foi transferido para erlenmeyer e $10 \mathrm{~mL}$ de metanol foram adicionados. $\mathrm{O}$ extrato foi submetido à decocção durante 5 minutos, resfriado e filtrado. Do filtrado, alíquotas de $20 \mu \mathrm{L}$ foram retiradas e aplicadas em placas de sílica gel $60-\mathrm{F}_{254}$ (Macherey-Nagel ${ }^{\circledR}$ ). As cromatoplacas foram obtidas através da metodologia descrita por Wagner e Bladt (1996). O quadro 1 mostra os sistemas de eluição, reveladores e padrões utilizados para cada classe de metabólito em estudo. Após eluição, as cromatoplacas foram secas em capela e observadas sob luz branca. Em seguida, foram derivatizadas e observadas nos comprimentos de onda de $254 \mathrm{~nm}$ e $366 \mathrm{~nm}$.

Quadro 1 - Sistemas de eluição, reveladores e padrões utilizados para cada classe de metabólito.

\begin{tabular}{|c|c|c|c|}
\hline Metabólitos & Sistemas de eluição & Reveladores & Padrões \\
\hline Taninos condensados & \multirow{4}{*}{$\begin{array}{c}\text { AcOEt: } \mathrm{HCOOH}: \mathrm{H}_{2} \mathrm{O} \\
(90: 5: 5)\end{array}$} & $\mathrm{VC}$ & Catequina \\
\hline Taninos hidrolisáveis & & $\mathrm{FeCl}_{3}$ & Ác. gálico e Ác. Elágico \\
\hline Flavonoides & & \multirow{2}{*}{$\mathrm{AlCl}_{3}$} & Quercetina e Rutina \\
\hline Derivados cinâmicos & & & Ác. cafeico e Ác. clorogênico \\
\hline Cumarinas & $\begin{array}{c}\text { EtOEt:Tolueno:AcOH10\% } \\
(50: 50: 50)\end{array}$ & $\mathrm{KOH}+\mathrm{UV}$ & Cumarina \\
\hline Saponinas & $\begin{array}{c}\text { AcOEt:HCOOH:AcOH: } \mathrm{H}_{2} \mathrm{O} \\
(100: 11: 11: 26)\end{array}$ & $\mathrm{LB}+\Delta$ & Escina \\
\hline Terpenos e esteroides & Tolueno:AcOEt (70:30) & $\mathrm{LB}+\Delta$ & $\beta$-sitosterol \\
\hline Alcaloides & \multirow{2}{*}{$\begin{array}{c}\text { AcOEt:MeOH: } \mathrm{H}_{2} \mathrm{O} \\
(50: 6,75: 5)\end{array}$} & Dragendorff & Nitrato de pilocarpina \\
\hline Antraquinonas & & $\mathrm{HNO}_{3}+\mathrm{KOH}$ & Senosídeo A \\
\hline
\end{tabular}

AcOEt: Acetato de etila; $\mathrm{HCOOH}$ : Ácido fórmico, $\mathrm{H}_{2} \mathrm{O}$ : Água, AcOH: Ácido acético, EtOEt: Éter etílico; UV: Ultravioleta; VC: Vanilina Clorídrica; $\mathrm{FeCl}_{3}$ : Cloreto férrico; $\mathrm{AlCl}_{3}$ : Cloreto de alumínio; $\mathrm{LB}$ : Lieberman Burchard; $\mathrm{H}_{2} \mathrm{SO}_{4}$ : Ácido Sulfúrico; $\mathrm{KOH}$ : Hidróxido de Potássio; $\mathrm{HNO}_{3}$ : Ácido Nítrico. 


\section{RESULTADOS E DISCUSSÃO}

A prospecção fitoquímica indicou a presença de diversos grupos de constituintes químicos provenientes do metabolismo secundário. Os resultados foram positivos para taninos condensados e hidrolisáveis, flavonoides, derivados cinâmicos, saponinas, terpenos e esteroides. Estes achados corroboram com estudos realizados por Das e Barman (2012) que identificaram a presença de taninos hidrolisáveis e flavonoides nos extratos das folhas de $P$. granatum.

A tabela 1 mostra a classe dos metabólitos secundários considerados positivos para a espécie com os respectivos valores de $\mathrm{Rfs}$ obtidos. Foi verificado que o $\mathrm{Rf}$ do padrão catequina para taninos condensados apresentou valor próximo para o extrato metanólico correspondendo, respectivamente, a 0,65 e 0,60 . Para saponinas, o Rf do padrão escina $(0,60)$ também apresentou valor aproximado ao do extrato $(0,62)$. Enquanto os demais metabólitos positivos, apresentaram bandas de mesma coloração após derivatização. Para cumarinas, alcaloides e antraquinonas não foram evidenciados bandas com coloração semelhante as dos padrões, demostrando a ausência desses fitoconstituintes na espécie.

Tabela 1 - Valores de Rf calculados para as bandas correspondentes aos padrões e bandas evidenciadas no extrato metanólico.

\begin{tabular}{|c|c|c|}
\hline Metabólitos & Rf padrão & Rfs amostra \\
\hline Taninos condensados & 0,65 & 0,60 \\
\hline Taninos hidrolisáveis & 0,60 & 0,$25 ; 0,45$ \\
\hline Flavonoides & 0,25 & 0,35 \\
\hline Dericavos cinâmicos & 0,50 & 0,37 \\
\hline Saponina & 0,60 & 0,62 \\
\hline
\end{tabular}

\section{CONCLUSÃO}

Os resultados da triagem fitoquímica a partir das folhas de Punica granatum por CCD sugere a presença de taninos (condensados e hidrolisáveis), flavonoides, derivados cinâmicos, açucares redutores, saponinas, terpenos e esteroides. Após confirmação da presença de metabólitos de interesse farmacológico, as perspectivas são a realização de estudos quantitativos com a finalidade de contribuir para o controle de qualidade da espécie.

\section{REFERÊNCIAS}

DAS, S.; BARMAN, S. Antidiabetic and antihyperlipidemic effects of ethanolic extract of leaves of Punica granatum in alloxan-induced non-insulin-dependent diabetes mellitus albino rats. Indian J Pharmacol., v. 44, p. 219-224, 2012.

FREITAS, A. V. L. et. al. Diversidade e usos de plantas medicinais nos quintais da comunidade de São João da Várzea em Mossoró, RN. Rev. Bras. Pl. Med., v. 17, n. 4, p. 845 $856,2015$.

FRIAS, D. F. R.; KOZUSNY-ANDREANI, D. I. Avaliação in vitro da atividade antifúngica de extratos de plantas e óleo de eucalipto sobre Trichophyton mentagrophytes. Rev. Bras. Pl. Med., v. 11, n. 2, p. 216-220, 2009.

JURENKA, J. S. Therapeutic applications of pomegranate (Punica granatum L.): a review. 
Altern Med Rev., v. 13, p. 28-44, 2008.

LINI, R. S. et al. Caracterização de fármacos por cromatografia em camada delgada. Rev. Bras. Farm., v. 95, n. 1, p. 486-498, 2014.

SARATELE, R. G. et al. Exploiting antidiabetic activity of silver nanoparticles synthesized using Punica granatum leaves and anticancer potential against human liver cancer cells (HepG2). Artif Cells Nanomed Biotechnol., v. 45, p. 1-12, 2017.

WAGNER, H.; BLADT, S. Plant Drug Analysis. A Thin Layer Chromatography. 2. ed. Berlim: Springer, 1996.

\section{AGRADECIMENTOS}

Os integrantes agradecem a FACEPE (APQ-0493- 4.03/14; BIC-0529-4.03/17) e ao CNPq (308386/2015-9). 